\title{
Contribution of $\mathrm{Ca}^{2+}$-Influx to Generation of the Transient Inward Current in Guinea-Pig Ventricular Muscles
}

\author{
Masayasu Hiraoka, Seiko Kawano, and Hiroyuki Kinoshita \\ Department of Cardiovascular Diseases, Medical Research Institute, \\ Tokyo Medical and Dental University, \\ Bunkyo-ku, Tokyo, 113 Japan
}

\begin{abstract}
Contribution of $\mathrm{Ca}^{2+}$-influx via the slow channel to generation of the transient inward current in guinea-pig ventricular muscles was studied using a single sucrose gap voltage clamp technique. The transient inward current (TI) was induced from superfusion of the preparations with the low $-\mathrm{K}^{+}(0 \mathrm{mM})$, high- $\mathrm{Ca}^{2+}(3.6 \mathrm{~mm})$ solution. Application of $2 \mathrm{mM}-\mathrm{Co}^{2+}$ quickly and reversibly suppressed the TI amplitude to $25 \%$ of the control and delayed its peak timing to $153 \%$ during $10-20 \mathrm{~min}$. Inhibition developed as quickly as $\mathrm{Co}^{2+}$ suppressed the slow inward current $\left(I_{\mathrm{s}}\right)$, and its recovery took place without apparent time lag behind its effect on $I_{\mathrm{s}}$. The block of both TI and $I_{\mathrm{s}}$ by $\mathrm{Co}^{2+}$ was antagonized by raising external $\mathrm{Ca}^{2+}$ to $7.2 \mathrm{~mm}$. Removal of external $\mathrm{Ca}^{2+}$ caused a prompt suppression of both $I_{\mathrm{s}}$ and TI. Application of 2 or $5 \mathrm{~mm}$-procaine $\mathrm{HCl}$ produced a complete abolition of TI with a mild depression of $I_{\mathrm{s}}$. While $1 \mathrm{mM}$-caffeic caused a suppression of TI after a transient augmentation, $10 \mathrm{~mm}$-caffeine completely eliminated it without abolishing $I_{\mathrm{s}}$. These results indicate that the $\mathrm{Ca}^{2+}$-influx through the slow channel acts not only to load the cell with those ions, but also to influence somehow the $\mathrm{Ca}^{2+}$-release from the stores under the $\mathrm{Ca}^{2+}$-overloaded conditions.
\end{abstract}

Key words: delayed afterdepolarizations, $\mathrm{Ca}^{2+}$-overload, $\mathrm{Ca}^{2+}$-release, slow inward current.

When cardiac muscles are overloaded with $\mathrm{Ca}$ by means of various interventions, they develop delayed afterdepolarizations (DADs) and aftercontractions (FERrier and MoE, 1973; FERrIER, 1977; KASS et al., 1978a, b; EISNER and LEDERER, 1979; MATSUDA et al., 1982); DADs are produced by the transient inward current (TI) (LEDERER and TSIEN, 1976). The mechanism of TI was suggested to be phasic changes in the internal calcium concentration, possibly reflecting cyclic release of $\mathrm{Ca}^{2+}$ from the intracellular stores (KASS et al., 1978a, b). Oscillations of

Received for publication December 23, 1986 
the intracellular free $\mathrm{Ca}$ concentration $\left(\left[\mathrm{Ca}^{2+}\right]_{\mathrm{i}}\right)$ have recently been demonstrated using the aequorin signal during elevated $\left[\mathrm{Ca}^{2+}\right]_{\mathrm{i}}$ (WIER et al., 1983; ALLEN et al., 1984).

Since FERRIER and MOE (1973) first described the inhibitory action of $\mathrm{Mn}^{2+}$ on DADs, various $\mathrm{Ca}^{2+}$-channel blocking agents have been shown to suppress both DADs and TI (Kass et al., 1978a; EISNER and LEDERER, 1979; KARAGUEUZIAN and KATZUNG, 1982; KASS and Tsien, 1982). Kass et al., (1978a) proposed that the main action of $\mathrm{Mn}^{2+}$ and of D-600 was to reduce $\mathrm{TI}$, indirectly, through their effects on the slow inward current $\left(I_{\mathrm{s}}\right)$, thus eliminating the $\mathrm{Ca}^{2+}$-overload in the cell. The same idea was also applied to the inhibitory action of verapamil on TI (KARAGUEUZIAN and KATZUNG, 1982). It has been pointed out, however, that $\mathrm{Ca}^{2+}$ transported through the slow channel enters into a confined space where, in turn, it triggers the release of $\mathrm{Ca}$ from the sarcoplasmic reticulum, a major site of the stores (FABIATO, 1983). Furthermore, DADs and TI were induced in the wake of a train of action potentials or upon repolarization from preceding depolarizing clamp pulses (LEDERER and TsIEN, 1976). These results may indicate that $\mathrm{Ca}$ ions entering into the cell via the slow channel upon each depolarization can, somehow, influence the amplitude and the time course of TI following the repolarization. Therefore, the question may be asked as to whether $I_{\mathrm{s}}$ is a direct trigger for TI, or whether it is a sole mechanism for cell loading with $\mathrm{Ca}^{2+}$. To approach this question, the effects of $\mathrm{Co}^{2+}$ as an inhibitor of $I_{\mathrm{s}}$ (KoHLHARDT and HAAP, 1980) and other agents on TI, were examined using a single sucrose gap voltage clamp technique in guinea-pig ventricular muscles. In this study, the TI was induced in the muscle preparations from superfusing with the low- $\mathrm{K}^{+}$, high- $\mathrm{Ca}^{2+}$ solution, which was shown to be an easy and reproducible method for the study of this current in muscle preparations (EISNER and LeDERER, 1979; HiRAOKA et al., 1979, 1981). A preliminary report of this work appeared elsewhere (KAWANo et al., 1985).

\section{METHODS}

Preparations. Guinea-pigs weighing 250-350 g were stunned with a blow on the neck, and their hearts were rapidly removed through a thoracotomy. Papillary muscles of suitable dimensions (length longer than $4 \mathrm{~mm}$, diameter less than $0.7 \mathrm{~mm}$ ) were dissected from the right ventricle. To handle the preparation, a fine silk thread was tied to the tendinous end of the preparation.

Solutions. The modified Tyrode's solution had the following composition (mM): $\mathrm{NaCl} 150 ; \mathrm{KCl} 4.0 ; \mathrm{CaCl}_{2} 1.8 ; \mathrm{MgCl}_{2} 1.0 ;$ Tris- $\mathrm{HCl} 10.0$; glucose $5.5 ; \mathrm{pH}$ adjusted to 7.3 by titration with $\mathrm{NaOH}$. The low- $\mathrm{K}^{+}$, high- $\mathrm{Ca}^{2+}$ solution had $0 \mathrm{~mm}$ $\mathrm{KCl}$ and $3.6 \mathrm{~mm} \mathrm{CaCl}_{2}$, and other compositions were the same as the modified Tyrode's solution. The $\mathrm{Co}^{2+}$-containing solution was prepared by adding $2 \mathrm{~mm}$ $\mathrm{CoCl}_{2}$ in the low-K ${ }^{+}$, high-Ca ${ }^{2+}$ solution. To vary $\mathrm{Ca}^{2+}$ concentration of the solutions, $\mathrm{CaCl}_{2}$ was added or removed from the low-K ${ }^{+}$, high-Ca ${ }^{2+}$ solution with or without $\mathrm{CoCl}_{2}$. No osmolarity correction was made with these solutions. In some 
experiments, caffeine (Wako Pure Chemical Ind., 1 or $10 \mathrm{~mm}$ ) and procaine $\mathrm{HCl}$ (Maruishi Pharm. Co., 2 or $5 \mathrm{~mm}$ ) were added to the low-K ${ }^{+}$, high-Ca ${ }^{2+}$ solution. The $\mathrm{pH}$ of all these solutions was $7.2-7.4$ by continuous bubbling with $100 \% \mathrm{O}_{2}$. The isotonic $\mathrm{KCl}$ solution was made by substituting $\mathrm{KCl}$ for $\mathrm{NaCl}$ in the Tyrode's solution. The isotonic sucrose solution contained 292 sucrose, 5.5 glucose, and 0.05 $\mathrm{CaCl}_{2}$. All these solutions were gassed with $100 \% \mathrm{O}_{2}$ throughout the experiments. The temperature of the superfusates was maintained at $36-37^{\circ} \mathrm{C}$.

Experimental setup. In the single sucrose-gap voltage clamp experiments, the ventricular preparations were mounted into a three-compartment chamber similar to that described previously (HIRANO and HiraOKA, 1986). After mounting the preparation in the chamber, all of the three compartments were superfused with the Tyrode's solution for an equilibration period of $30 \mathrm{~min}$. At the end of this period, the superfusing fluid in the sucrose gap and in the current injection pool was replaced by the isotonic sucrose and by the $\mathrm{KCl}$ solution, respectively. The effectiveness of the sucrose gap as a seal was judged from comparing the amplitude of the action potential recorded intracellularly $\left(\mathrm{AP}_{\mathrm{i}}\right)$ and the one extracellularly $\left(\mathrm{AP}_{\mathrm{o}}\right)$. The ratio $\mathrm{AP}_{\mathrm{i}} / \mathrm{AP}_{\mathrm{o}}$ below 1.15 was decided to be a good sealing and selected to be used in further experiments. Experimental procedures and check of the adequacy of the voltage control were, similar to those described in the previous report (HIRANO and HiRAOKA, 1986). Records of membrane potentials and currents were displayed on an oscilloscope (VC-10, Nihon Kohden, Tokyo) and photographed with a camera (PC 2B, Nihon Kohden, Tokyo) or inscribed with a directwriting recorder (Recti-Horiz 8K, San-ei Sokki, Tokyo). The preparation was stimulated at a frequency of $0.2 \mathrm{~Hz}$. The stimuli were supplied from the pulse generator (SEN-7103, Nihon Kohden, Tokyo).

Induction of the transient inward current. To induce TI, the superfusing fluid in the test compartment was changed from the modified Tyrode's solution to the low- $\mathrm{K}^{+}$, high- $\mathrm{Ca}^{2+}$ solution, as we used in the induction of the delayed afterdepolarizations (HIRAOKA et al., 1979, 1981, see also EISNER and LEDERER, 1979). The muscle fibers were stimulated with rectangular pulses of supra-threshold intensity at a frequency of $0.2 \mathrm{~Hz}$, and they were placed under the voltage clamp condition every $5 \mathrm{~min}$ in this superfusate. The preparations usually began to develop TI during the voltage clamp condition after $10-15 \mathrm{~min}$ in the low- $\mathrm{K}^{+}$, high-Ca ${ }^{2+}$ solution. The amplitude and time courses of TI became large enough to be measurable with repeated applications of clamp pulses after $30 \mathrm{~min}$ of the low- $\mathrm{K}^{+}$, high- $\mathrm{Ca}^{2+}$ superfusion. Under this condition, the current measurements were done in the control and in the $\mathrm{Co}^{2+}$ - or drug-containing solutions.

The measurement of TI in the present experiment was done after repolarization from depolarizing pulses to the holding potential of -45 to $-35 \mathrm{mV}$. A low level of the holding potential was chosen so as to inactivate the fast $\mathrm{Na}^{+}$current and to avoid the non-homogeneous space clamp during the flow of this current. The regular clamp pulses of a 1-s duration were given at a frequency of $0.2 \mathrm{~Hz}$. The amplitude of $\mathrm{TI}$ was measured with respect to an up-sloping or a down-sloping 
baseline drawn tangent to two positive peaks which flanked the trough (see, Fig. 2B, inset). The peak timing of TI was an interval between the end of the depolarizing pulse and the peak of the largest TI. The amplitude of $I_{\mathrm{s}}$ was measured according to the method proposed by MCDonald and Trautwein (1978) in cat ventricular muscles. The data collection was made when the stable microelectrode impalement was maintained during the application of $\mathrm{Co}^{2+}$ and other agents.

Statistical analysis. The data were expressed as a mean \pm standard error of mean (M.S.E.). The statistical analysis was performed using the paired $t$-test. A $p$ value less than 0.05 was considered to be significant.

\section{RESULTS}

When depolarizing pulses of a 1-s duration were applied from the holding potential about $-40 \mathrm{mV}$, several inward deflections of the current trace, the TIs, superimposing on the tail current were observed. In the present experiment, TI usually developed on the decaying outward tail current (see, Fig. 1) but it was also seen on the inward tail current on some occasions. When $2 \mathrm{~mm}-\mathrm{Co}^{2+}$ was applied to the preparations, the current was rapidly suppressed. The amplitude of TI became less than $30 \%$ of the control value at $10-20 \mathrm{~min}$ in the $\mathrm{Co}^{2+}$-solution. Figure 1 shows voltage clamp records demonstrating the depressive action of $\mathrm{Co}^{2+}$ on TI. The $\mathrm{Co}^{2+}$ not only depressed the TI amplitude but also delayed its peak timing (Fig. 1B). These changes in TI recovered to the control level after the wash-out of $\mathrm{Co}^{2+}$ (Fig. 1C). Table 1 summarizes the $\mathrm{Co}^{2+}$ effect during the 10-20-min application obtained from 7 preparations. The $2 \mathrm{~mm}-\mathrm{Co}^{2+}$ decreased the TI amplitude to $25 \pm 5 \%$ (mean \pm M.S.E.) of the control and prolonged the peak timing to
(A) Before $\mathrm{Co}^{2+}$
(B) $2 \mathrm{mM} \mathrm{Co} \mathrm{Co}^{2+} 15 \mathrm{~min}$.
(C) Wash-out $\mathrm{Co}^{2+}$

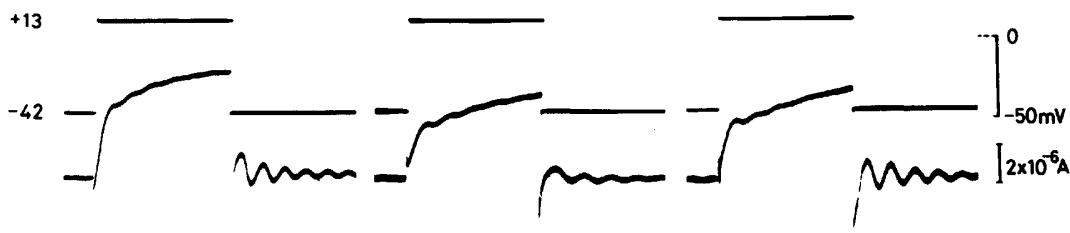

$5 \overleftrightarrow{00 \mathrm{msec}}$.

Fig. 1. Effect of $2 \mathrm{mM}-\mathrm{Co}^{2+}$ on the membrane current of the guinea-pig ventricular muscle during the low- $\mathrm{K}^{+}$, high- $\mathrm{Ca}^{2+}$ superfusion. In each picture, the upper trace represents the voltage and the lower is the membrane current. A 1-s pulse was applied from the holding potential of -42 to $+13 \mathrm{mV}$ at the upper and to $0 \mathrm{mV}$ at the bottom row. In the control before application of $\mathrm{Co}^{2+}(\mathrm{A})$, the TIs of several fluctuations were observed upon repolarization to $-42 \mathrm{mV}$ from the depolarizing pulses. They were largely suppressed by the application of $2 \mathrm{mM}_{-} \mathrm{Co}^{2+}$ (B). The wash-out of $\mathrm{Co}^{2+}$ caused a reappearance of the TI (C). The records in $\mathrm{C}$ were obtained at $15 \mathrm{~min}$ in the $\mathrm{Co}^{2+}$-free solution. 
Table 1. Effects of $\mathrm{Co}^{2+}$ on the TI.

\begin{tabular}{|c|c|c|c|c|c|c|c|}
\hline & \multicolumn{3}{|c|}{ Amplitude of TI } & & \multicolumn{3}{|c|}{ Peak timing of TI } \\
\hline & $\begin{array}{l}\text { Before } \\
\mathrm{Co}^{2+}\end{array}$ & $\begin{array}{l}\mathrm{Co}^{2+} \\
2 \mathrm{mM}\end{array}$ & $\begin{array}{c}\text { Wash-out } \\
\mathrm{Co}^{2+}\end{array}$ & & $\begin{array}{l}\text { Before } \\
\mathrm{Co}^{2+}\end{array}$ & $\begin{array}{l}\mathrm{Co}^{2+} \\
2 \mathrm{mi}\end{array}$ & $\begin{array}{c}\text { Wash-out } \\
\mathrm{Co}^{2+}\end{array}$ \\
\hline $\begin{array}{c}\times 10^{-7} \mathrm{~A} \\
\%\end{array}$ & $\begin{array}{c}22.2 \pm 5.1 \\
100\end{array}$ & $\begin{array}{c}3.9 \pm 1.4 \\
25 \pm 5\end{array}$ & $\begin{array}{c}25.8 \pm 7.4 \\
114 \pm 8\end{array}$ & $\begin{array}{c}\mathrm{ms} \\
\%\end{array}$ & $\begin{array}{c}187 \pm 9.3 \\
100\end{array}$ & $\begin{array}{r}281.2 \pm 29 \\
153 \pm 13\end{array}$ & $\begin{array}{c}7209.4 \pm 11.5 \\
116 \pm 6\end{array}$ \\
\hline$p$ value & \llcorner & $\begin{array}{ll}* \\
\text { NS }\end{array}$ & * & $p$ value & $L$ & 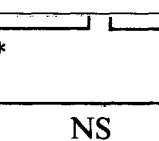 & $\begin{array}{ll}* \\
\end{array}$ \\
\hline
\end{tabular}

$n=7 . * p<0.05$. NS, not significant.

(A)
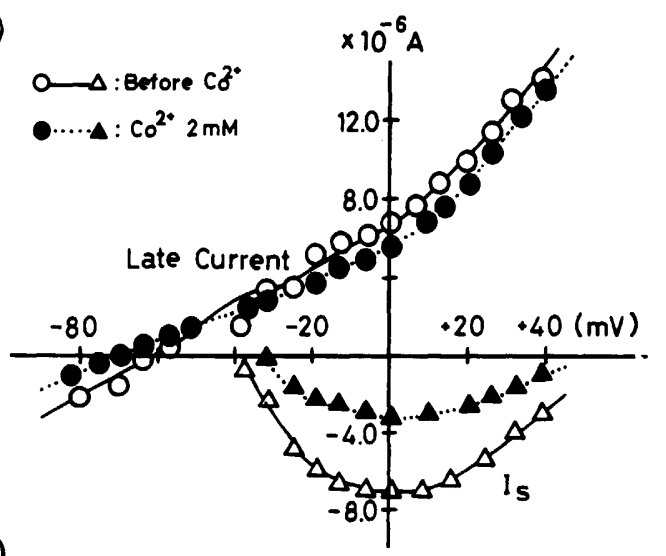

(B)

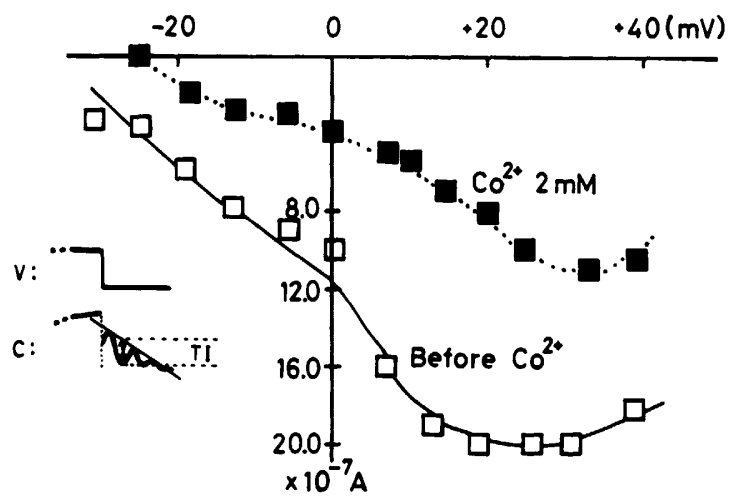

Fig. 2. Effects of $\mathrm{Co}^{2+}$ on the current-voltage relationships of the guinea-pig ventricular muscle in the low- $\mathrm{K}^{+}$, high- $\mathrm{Ca}^{2+}$ solution. A: shows the current-voltage relationships of the late current $(O, \bullet)$ and of $I_{\mathrm{s}}(\triangle, \mathbf{\Delta})$. B: represents the TIactivation voltage relationship obtained before $(\square)$ and during $(\square)$ the application of $2 \mathrm{mM}-\mathrm{Co}^{2+}$. The inset indicates how to measure the amplitude of TI. 
$153 \pm 13 \%$. These changes recovered completely upon the wash-out of $\mathrm{Co}^{2+}$. In 3 fibers, the exposure to the $\mathrm{Co}^{2+}$ solution was extended to $30 \mathrm{~min}$. The amplitude of TI decreased to $23 \%$ (mean) of the control at $10 \mathrm{~min}$ and it was $27 \%$ at $20 \mathrm{~min}$, and $31 \%$ at 30 min during the $\mathrm{Co}^{2+}$ application. Thus, no further depression of TI with the exposure to $\mathrm{Co}^{2+}$ longer than $20 \mathrm{~min}$ was noted but it showed a tendency to recover at a later exposure time. This is partly due to a non-steady condition of the $0 \mathrm{~mm}-\mathrm{K}^{+}$solution used in this experiment.

Figure 1 also demonstrates effects of $\mathrm{Co}^{2+}$ on currents other than TI under this condition. $I_{\mathrm{s}}$ showed a decreased amplitude as well as its peak value during the $\mathrm{Co}^{2+}$ application (Fig. 1 B). Its amplitude became about $50 \%$ of the control. There was no complete inhibition of $I_{\mathrm{s}}$ during $10-20 \mathrm{~min}$ in the $\mathrm{Co}^{2+}$ solution with 7 examined preparations. This is probably due to a high- $\mathrm{Ca}^{2+}$ concentration used in the present experiment, since the block of $I_{\mathrm{s}}$ by $\mathrm{Co}^{2+}$ was dependent on $\left[\mathrm{Ca}^{2+}\right]_{\mathrm{o}}$ (KoHLHARDT and HAAP, 1980). The wash-out of $\mathrm{Co}^{2+}$ during $15 \mathrm{~min}$ produced an incomplete recovery of $I_{\mathrm{s}}$ in this preparation. Another feature of the $\mathrm{Co}^{2+}$ effect was a depression of late outward current and of outward tail current upon repolarization. The changes in the outward current showed a tendency to recover after the wash-

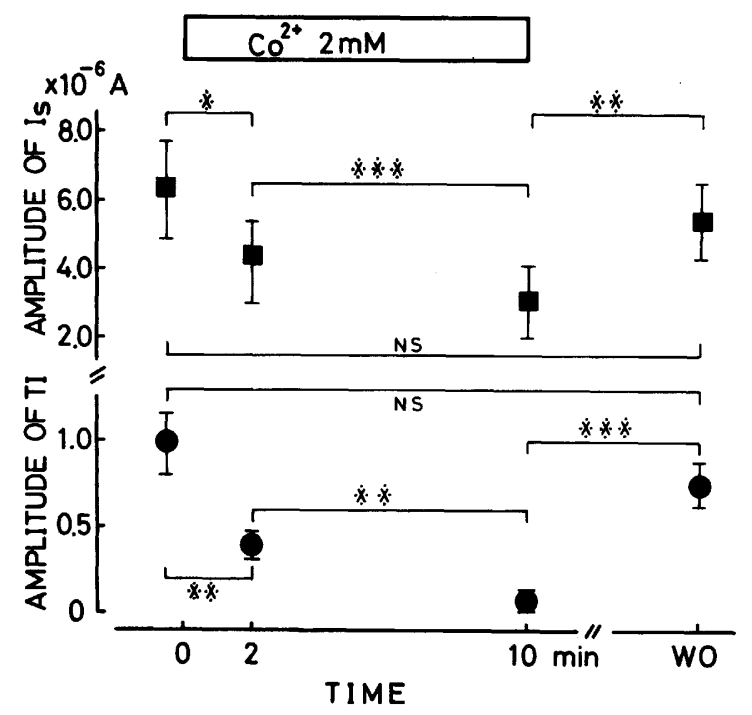

Fig. 3. Time course of changes in $I_{\mathrm{s}}$ and TI during and after the application of $\mathrm{Co}^{2+}$. In the ordinate, the upper row represents the amplitude of $I_{\mathrm{s}}$ and the lower is that of TI. Depolarizing pulses to about $0 \mathrm{mV}$ with a 1-s duration were applied from the holding potential of about $-40 \mathrm{mV}$ in each experiment. The $I_{\mathrm{s}}$ induced by the depolarizing pulses and the TI upon repolarization to the holding potential were measured. Each point represents the mean of 7 experiments and vertical bars indicate \pm M.S.E. The abscissa shows the time and 0 time corresponds to the start of the $\mathrm{Co}^{2+}$ application. WO means the wash-out of $\mathrm{Co}^{2+}$ and its value was measured at $10-20 \mathrm{~min}$ in the $\mathrm{Co}^{2+}$-free solution. $* p<0.05, * * p<0.02$, $* * * p<0.01$. NS, not significant. 
out of $\mathrm{Co}^{2+}$ (Fig. 1C). Depression of the outward current by $\mathrm{Co}^{2+}$ and its recovery were confirmed in 6 other preparations.

Figure 2 demonstrates the current-voltage relationships in this condition and the effects of $\mathrm{Co}^{2+}$ on them. While the late current, which was expressed as the amplitude at the end of 1-s pulse, was slighty depressed, $I_{\mathrm{s}}$ was markedly inhibited by $\mathrm{Co}^{2+}$ at all potentials (Fig. 2A); Fig. 2B shows the dependence of TI on the activation voltage and the effect of $\mathrm{Co}^{2+}$ on it. During the control, the TI amplitude increased with depolarization of activating pulses up to about $+20-+30 \mathrm{mV}$ Further depolarizing steps caused a depression of the amplitude of TI, which confirmed the previous observation in ventricular muscles (KARAGUEUZIAN and KATZUNG, 1982). The peak value of TI was obtained at $+29 \mathrm{mV}$ of the activation voltage in average from 7 preparations. This value was positive by $25 \mathrm{mV}$ compared to that of $I_{\mathrm{s}}$ (about $+3 \mathrm{mV}$, see also Fig. 2A). The application of $\mathrm{Co}^{2+}$ depressed TI at all voltages and flattened the relationship between the activation voltage and TI.

Since $\mathrm{Co}^{2+}$ exhibited a quick depressive action on TI as it blocked $I_{\mathrm{s}}$ (KOHLHARDT and HAAP, 1980), its effects on both $I_{\mathrm{s}}$ and TI were examined with another 7 preparations during short exposure (Fig. 3). At $2 \mathrm{~min}$ in the $\mathrm{Co}^{2+}$ solution, the amplitude of $I_{\mathrm{s}}$ had already significantly decreased to $71 \pm 5 \%$ of the control and that of TI did to $48 \pm 11 \%$. Thus, inhibitory action of $\mathrm{Co}^{2+}$ on TI

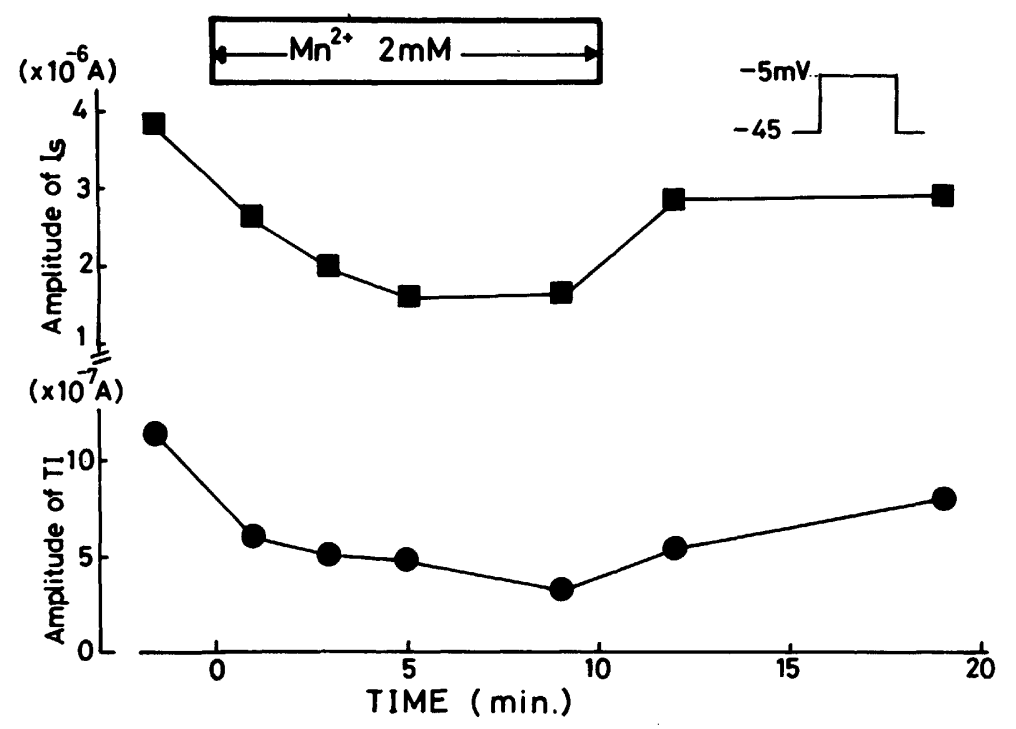

Fig. 4. Time course of changes in $I_{\mathrm{s}}$ and TI during and after the application of $2 \mathrm{mM}$ $\mathrm{Mn}^{2+}$. The result was obtained from a single preparation. The fiber was voltageclamped at the holding potential of $-45 \mathrm{mV}$ and a depolarizing pulse to $-5 \mathrm{mV}$ with a 1-s duration was applied. The $I_{\mathrm{s}}$ (upper) was measured from the response to the depolarizing pulse and the TI (lower) upon repolarization from the preceding depolarization at indicated time. During the rest of the time, the fiber was offclamped and stimulated with a rectangular pulse at $0.2 \mathrm{~Hz}$. 
became manifest and developed with a time course similar to those on $I_{\mathrm{s}}$. The amplitude of $I_{\mathrm{s}}$ decreased to $42 \pm 9 \%$ and that of TI to $14 \pm 7 \%$ at $10 \mathrm{~min}$ in the $\mathrm{Co}^{2+}$ solution. These changes recovered to the control level after the wash-out of $\mathrm{Co}^{2+}$ for 10-20 min. No time lag as to the recovery of TI as compared to that of $I_{\mathrm{s}}$ was noted. This result was somewhat different from the inhibitory actions of $\mathrm{Mn}^{2+}$ on both currents in digitalized Purkinje fibers as reported by KASS et al. (1978a). They found that the development and removal of the TI inhibition by $\mathrm{Mn}^{2+}$ lagged far behind its effect on the $I_{\mathrm{s}}$. Therefore, the action of $\mathrm{Mn}^{2+}$ on both currents was compared in our preparations. Fugure 4 demonstrates the time course of changes in

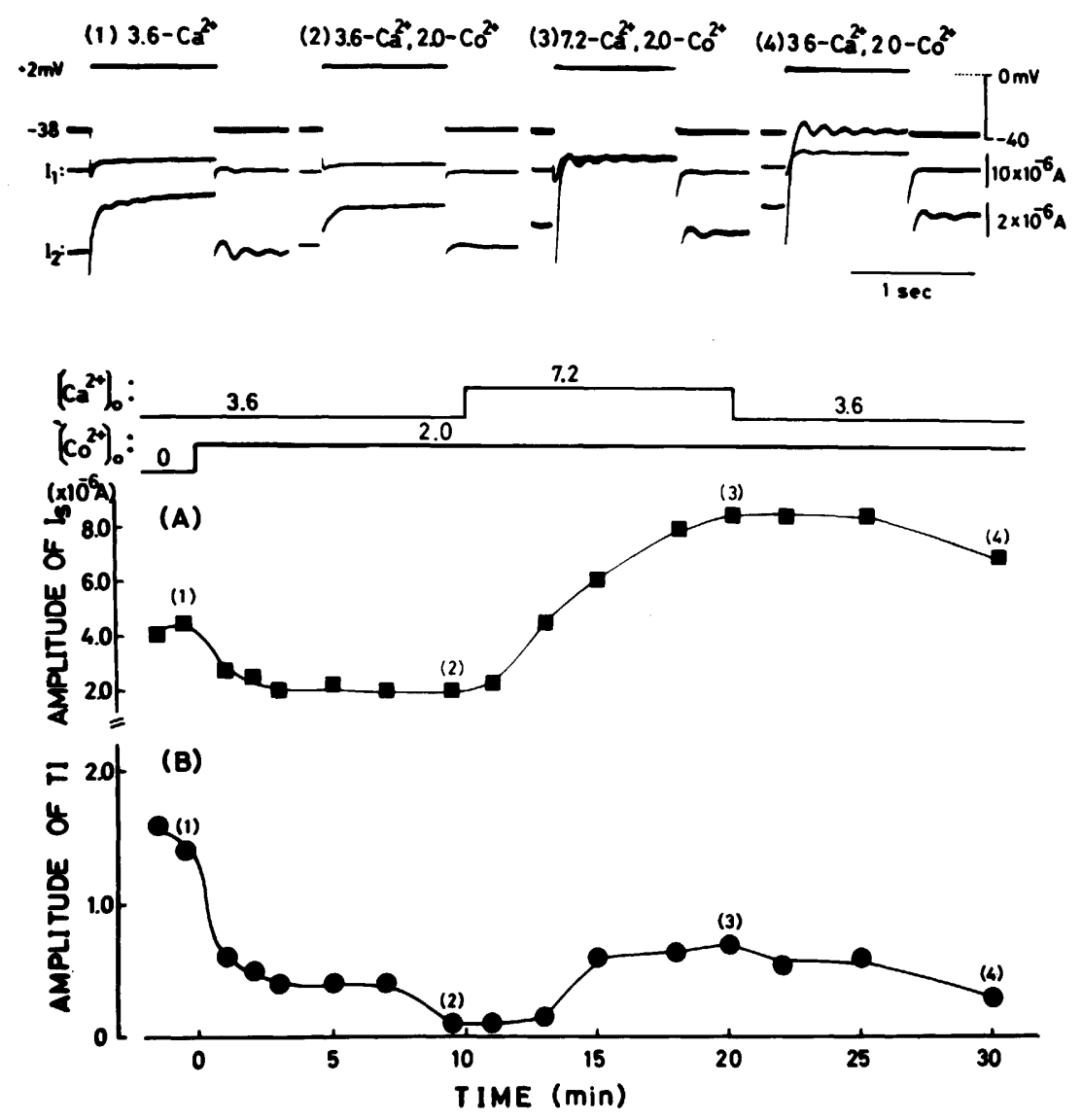

Fig. 5. Time course of changes in $I_{\mathrm{s}}$ and TI during the elevation of external $\mathrm{Ca}^{2+}$ in the presence of $\mathrm{Co}^{2+}$. The upper half represents the voltage clamp records obtained at the indicated time in the lower graph. In each picture, the top trace shows the voltage, the middle is the current with low magnification and the bottom that with high magnification. The lower half is graphs of $I_{\mathrm{s}}$ and TI with application of $\mathrm{Co}^{2+}$ and of high $\mathrm{Ca}^{2+}$. The concentrations of $\left[\mathrm{Ca}^{2+}\right]_{0}$ and of $\left[\mathrm{Co}^{2+}\right]_{\mathrm{o}}$ are shown by the two top lines. The experimental protocol was similar to those shown in Figs. 3 and 4. 
both currents after the application of $2 \mathrm{~mm}-\mathrm{Mn}^{2+}$ in a single preparation. The development and removal of the inhibition on both $I_{s}$ and TI appeared with similar time courses. This result was confirmed in 4 preparations. The TI decreased from $0.73 \pm 0.11 \mu \mathrm{A}$ in the control to $0.45 \pm 0.06 \mu \mathrm{A}$ at $1-2 \mathrm{~min}$ in the $\mathrm{Mn}^{2+}$ solution and it became $0.38 \pm 0.06 \mu \mathrm{A}$ at $10 \mathrm{~min}$. Compared to the control value, the level of TI was $64 \pm 7 \%$ at $1-2 \mathrm{~min}$ and $57 \pm 13 \%$ at $10 \mathrm{~min}$. The latter two values were significantly smaller than the former $\left(p<0.02\right.$ and $p<0.05$, respectively). The $I_{\mathrm{s}}$ decreased to $72 \pm 8$ and $65 \pm 11 \%$ of the control at 2 and $10 \mathrm{~min}$, respectively. The wash-out of $\mathrm{Mn}^{2}+$ caused a prompt recovery of TI and its amplitude restored to $92 \pm 8 \%$ of the control at $15 \mathrm{~min}$ in the $\mathrm{Mn}^{2+}$-free solution. The $I_{\mathrm{s}}$ recovered to $102 \pm 9 \%$ during the same wash-out period. Therefore, the development and removal of the $\mathrm{TI}$ inhibition after a short exposure to $\mathrm{Mn}^{2+}$ appeared without a delay compared to those of the $I_{\mathrm{s}}$ inhibition.

Since a close correlation between the inhibition of $I_{\mathrm{s}}$ and that of TI seemed to be evident, effects of conditions which presumably increased or decreased the former were examined. For this purpose, first the extracellular Ca concentration was raised during the presence of $\mathrm{Co}^{2+}$, since the inhibitory effect of $\mathrm{Co}^{2+}$ on $I_{\mathrm{s}}$ could be antagonized by excess $\mathrm{Ca}^{2+}$ (KoHLHARDT and HAAP, 1980). Figure 5 demonstrates time course of changes in both $I_{\mathrm{s}}$ and $\mathrm{TI}$, and their analysis, when $\left[\mathrm{Ca}^{2+}\right]_{\mathrm{o}}$ was raised from 3.6 to $7.2 \mathrm{mM}$ in the presence of $2 \mathrm{mM}-\mathrm{Co}^{2+}$. Inhibition of both $I_{\mathrm{s}}$ and TI by $2 \mathrm{mM}-\mathrm{Co}^{2+}$ was removed by raising $\left[\mathrm{Ca}^{2+}\right]_{\mathrm{o}}$ to $7.2 \mathrm{mM}$ with similar time courses. This result was confirmed in 4 fibers examined with

Table 2. Effects of raising $\left[\mathrm{Ca}^{2+}\right]_{0}$ on $I_{\mathrm{s}}$ and $\mathrm{TI}$ in the presence of $\mathrm{Co}^{2+}$.

\begin{tabular}{|c|c|c|c|c|}
\hline & & $3.6 \mathrm{~mm}-\mathrm{Ca}^{2+}$ & $\begin{array}{c}3.6 \mathrm{~mm}-\mathrm{Ca}^{2+} \\
+ \\
2.0 \mathrm{mM}-\mathrm{Co}^{2+}\end{array}$ & $\begin{array}{c}7.2 \mathrm{mM}-\mathrm{Ca}^{2+} \\
+ \\
2.0 \mathrm{mM}^{2+\mathrm{Co}^{2+}}\end{array}$ \\
\hline \multirow{5}{*}{$I_{\mathrm{s}}$} & & & & $*$ \\
\hline & $\mu \mathrm{A}$ & $6.3 \pm 1.5$ & $4.8 \pm 1.3$ & $7.6 \pm 0.9$ \\
\hline & & & NS & . \\
\hline & $\%$ & 100 & $76 \pm 11$ & $112 \pm 12$ \\
\hline & & & NS & \\
\hline \multirow[t]{6}{*}{$\mathrm{TI}$} & & & & $*$ \\
\hline & $\mu \mathrm{A}$ & $1.26 \pm 0.38$ & $0.29 \pm 0.17$ & $\widehat{0.06 \pm 0.15}$ \\
\hline & & & * & \\
\hline & & & & $*$ \\
\hline & $\%$ & 100 & $20 \pm \longdiv { 8 }$ & $51 \pm 4$ \\
\hline & & & $* * *$ & \\
\hline
\end{tabular}

$n=4 . * p<0.05, * * p<0.02, * * * p<0.01$. NS, not significant. 


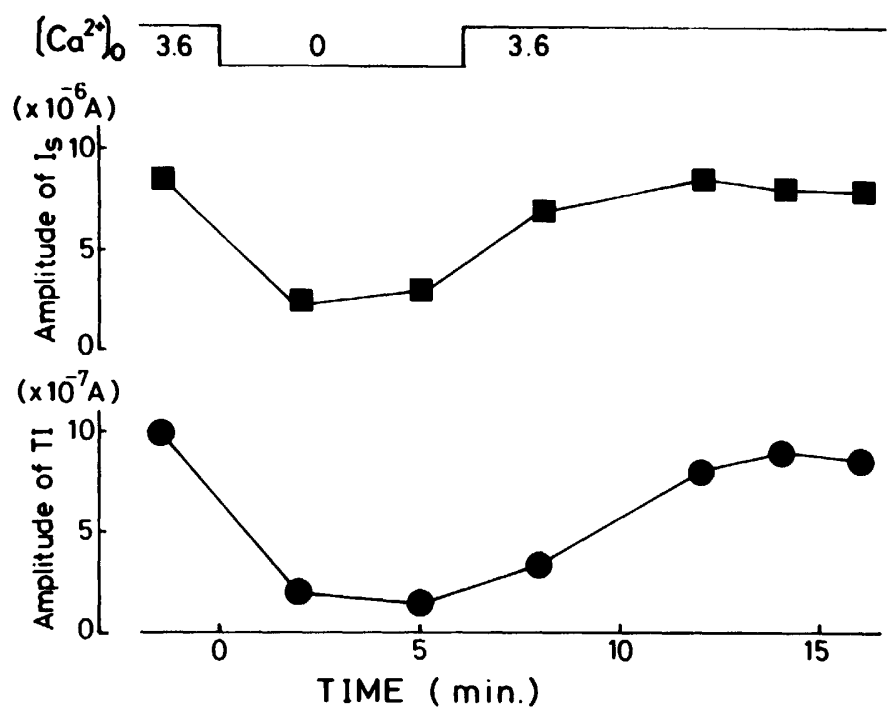

Fig. 6. Time course of changes in $I_{\mathrm{s}}$ and TI upon removal and readmission of $\left[\mathrm{Ca}^{2+}\right]_{0}$. $\left[\mathrm{Ca}^{2+}\right]_{0}$ is indicated at the top in mM. Experimental protocol, and measuring of $I_{\mathrm{s}}$ and of TI were similar to those in the previous figures.

the same protocol as that shown in Fig. 5. Table 2 shows the results of 4 experiments. In the control condition, the amplitude of $I_{\mathrm{s}}$ was $6.3 \pm 1.5 \mu \mathrm{A}$ and that of TI was $1.26 \pm 0.38 \mu \mathrm{A}$. The $I_{\mathrm{s}}$ and TI decreased to $76 \pm 11 \%$ and $20 \pm 8 \%$, respectively, in the $\mathrm{Co}^{2+}$ solution. Upon raising external $\left[\mathrm{Ca}^{2+}\right]$ to $7.2 \mathrm{~mm}$, the former recovered to $112 \pm 12 \%$ and the latter to $51 \pm 4 \%$. Therefore, both currents responded to high $\left[\mathrm{Ca}^{2+}\right]_{0}$ showing their recovery from the $\mathrm{Co}^{2+}$ effects, but a partial inhibition of TI continued despite a complete restoration of $I_{\mathrm{s}}$.

The second approach was to remove extracellular $\mathrm{Ca}^{2+}$ and to examine its effect on both $I_{\mathrm{s}}$ and TI. Figure 6 shows time course of changes in both currents upon removing $\left[\mathrm{Ca}^{2+}\right]_{0}$. The $0-\left[\mathrm{Ca}^{2+}\right]_{o}$ quickly inhibited both $I_{\mathrm{s}}$ and TI with similar time courses. After $6 \mathrm{~min}$ in the $\mathrm{Ca}^{2+}$-free solution, readmission of $3.6 \mathrm{mM}-\mathrm{Ca}^{2+}$ restored both currents to the control level. However, $0-\left[\mathrm{Ca}^{2+}\right]_{0}$ condition was prolonged to the period longer than $10 \mathrm{~min}$, the recovery of these currents was not complete and the trans-gap potential drastically decreased in these conditions. Therefore, the exposure to $0 \mathrm{mM}-\left[\mathrm{Ca}^{2+}\right]_{0}$ was limited to $6-8 \mathrm{~min}$ and the results obtained from 6 preparations are shown in Table 3. The $0-\left[\mathrm{Ca}^{2+}\right]_{\mathrm{o}}$ depressed $I_{\mathrm{s}}$ to $64 \pm 9 \%$ and TI to $50 \pm 11 \%$ during $1-2 \mathrm{~min}$. The former became $37 \pm 7 \%$ and the latter was $18 \pm 6 \%$, during $6-8 \mathrm{~min}$ in the $\mathrm{Ca}^{2+}$-free solution.

There have been several lines of evidence that an increase in intracellular $\mathrm{Ca}^{2+}$ plays a key role for the activation of TI. (KASS et al., 1978a, b; EISNER and LEDERER, 1979; KASS and TSIEN, 1982; MATSUDA et al., 1982). So far, our results indicate that the development and removal of TI are in good accord with those of $I_{\mathrm{s}}$ in their 
Table 3. Effects of $\mathrm{Ca}^{2+}$-removal on $I_{\mathrm{s}}$ and TI.

\begin{tabular}{|c|c|c|c|c|}
\hline & & $3.6 \mathrm{mM}-\left[\mathrm{Ca}^{2+}\right]_{\mathrm{o}}$ & $\begin{array}{c}0 \mathrm{~mm}-\left[\mathrm{Ca}^{2+}\right]_{o} \\
1-2 \mathrm{~min}\end{array}$ & $\begin{array}{c}0 \mathrm{mM}-\left[\mathrm{Ca}^{2+}\right]_{o} \\
6-8 \mathrm{~min}\end{array}$ \\
\hline \multirow{6}{*}{$I_{\mathrm{s}}$} & & & & $*$ \\
\hline & $\mu \mathrm{A}$ & $7.8 \pm 1.5$ & $4.6 \pm 0.8$ & $2.5 \pm 0.4$ \\
\hline & & & $* * *$ & \\
\hline & & & & $* *$ \\
\hline & $\%$ & 100 & $64 \pm 9$ & $37 \pm 7$ \\
\hline & & & $* * *$ & \\
\hline \multirow[t]{6}{*}{ TI } & & & & $*$ \\
\hline & $\mu \mathrm{A}$ & $2.45 \pm 0.98$ & $\overrightarrow{1.29} \pm 0.60$ & $0.42 \pm 0.15$ \\
\hline & & & $* *$ & \\
\hline & & & & $* *$ \\
\hline & $\%$ & 100 & $\overrightarrow{50} \pm 11$ & $18 \pm 6$ \\
\hline & & & *** & \\
\hline
\end{tabular}

$n=6 . * p<0.05, * * p<0.02, * * * p<0.01$.

timings. This may indicate that $\mathrm{Ca}^{2+}$ transported through the slow channel plays a role not only for the cell-loading with $\mathrm{Ca}^{2+}$, but also has some additional action in regulating the intracellular movement of those ions. As the latter possibility, it may be suggested that $\mathrm{Ca}^{2+}$-influx via $I_{\mathrm{s}}$, somehow affects the triggering mechanism of Ca-release from the sarcoplasmic reticulum. In order to examine the latter possibility, pharmacologic interventions which are believed to affect the $\mathrm{Ca}^{2+}$ release and -uptake mechanism from the sarcoplasmic reticulm were tested as to their effects on TI. Local anesthetics have been used to block $\mathrm{Ca}^{2+}$-release from the sarcoplasmic reticulum in skeletal muscle and they have been shown to exert similar actions on heart muscles as well (ENDO, 1977; CHAPMAN, 1979). Two mm-procaine $\mathrm{HCl}$ was found to eliminate TI completely with a mild reduction of $I_{\mathrm{s}}$ in 5 among 7 preparations (Fig. 7). The TI in the other 2 preparations was depressed to less than $25 \%$ of the control level. The $I_{\mathrm{s}}$ was suppressed to $68 \pm 12 \%$ of the control during the $10 \mathrm{~min}$ of the application in 7 fibers. Five mM-procaine was found to abolish the TI completely within $5 \mathrm{~min}$ of the application and also to suppress $I_{\mathrm{s}}$ to $48 \pm 9 \%$ of control. Thus, procaine at the concentration used in the present experiments was shown to depress $I_{\mathrm{s}}$ of ventricular muscles, in addition to its known action on the $\mathrm{Na}$ channel.

Caffeine is known to enhance the force of contraction in heart muscle as it does in skeletal muscle. This effect is attributed in part to increased $\mathrm{Ca}^{2+}$-release from the sarcoplasmic reticulum (ENDO, 1977). It also produces a prolongation of relaxation 
(A) Before Procaine

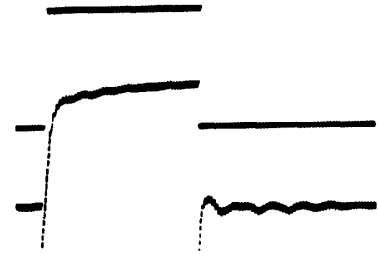

(B) $2 \mathrm{mM}$ Procaine $\mathrm{HCl}$

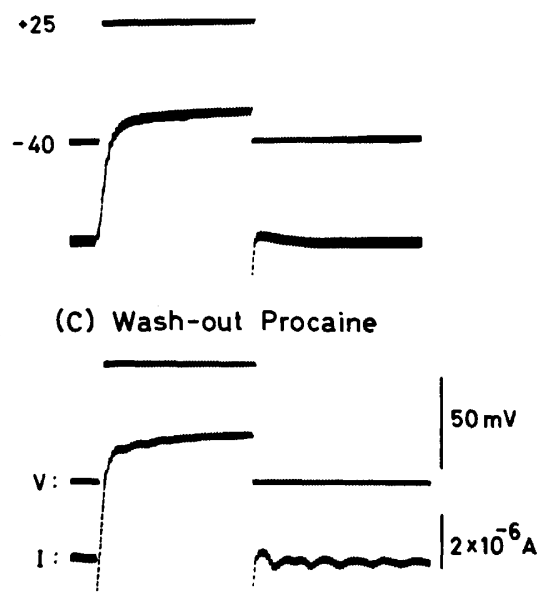

$\overline{500 \mathrm{~ms}}$

Fig. 7. Effect of $2 \mathrm{~mm}$-procaine on TI. Application of $2 \mathrm{~mm}$-procaine $\mathrm{HCl}$ completely eliminated TI with a mild depression of $I_{\mathrm{s}}(\mathrm{B})$. These changes were reversible upon the wash-out of procaine in $\mathrm{C}$.

and contracture, especially at high concentrations. The latter effect is postulated mainly to inhibit $\mathrm{Ca}^{2+}$-uptake by the sarcoplasmic reticulum, thus depleting its stores (ChApMAN, 1979; FABIATO, 1983). The application of 1 mM-caffeine was found to cause increased $I_{\mathrm{s}}$ and TI transiently, and to suppress both currents at later time of the application $(10 \mathrm{~min})$. Figure 8 shows time course of changes of the caffeine effects on both currents' systems in a single preparation. The TI increased from $0.53 \mu \mathrm{A}$ in the control to $0.71 \mu \mathrm{A}$ at $1 \mathrm{~min}$ of the application (Fig. 8B), while $I_{\mathrm{s}}$ increased from 1.53 to $2.0 \mu \mathrm{A}$. At $10 \mathrm{~min}$ of the caffeine treatment (Fig. 8C), TI decreased to $0.29 \mu \mathrm{A}$ and $I_{\mathrm{s}}$ to $1.41 \mu \mathrm{A}$. Transient increases in both $I_{\mathrm{s}}$ and TI were observed in 5 among 7 preparations within 2 min of the application while the other 2 were found to have increased $I_{\mathrm{s}}$ with decreased TI from the beginning of the caffeine-treatment. Upon the wash-out of $1 \mathrm{~mm}$-caffeine, TI quickly restored its amplitude beyond the control level (Fig. 8D) in the continued depression of $I_{\mathrm{s}}$. Later, the former showed a tendency to recover to the pre-treatment level (Fig. 8E). 


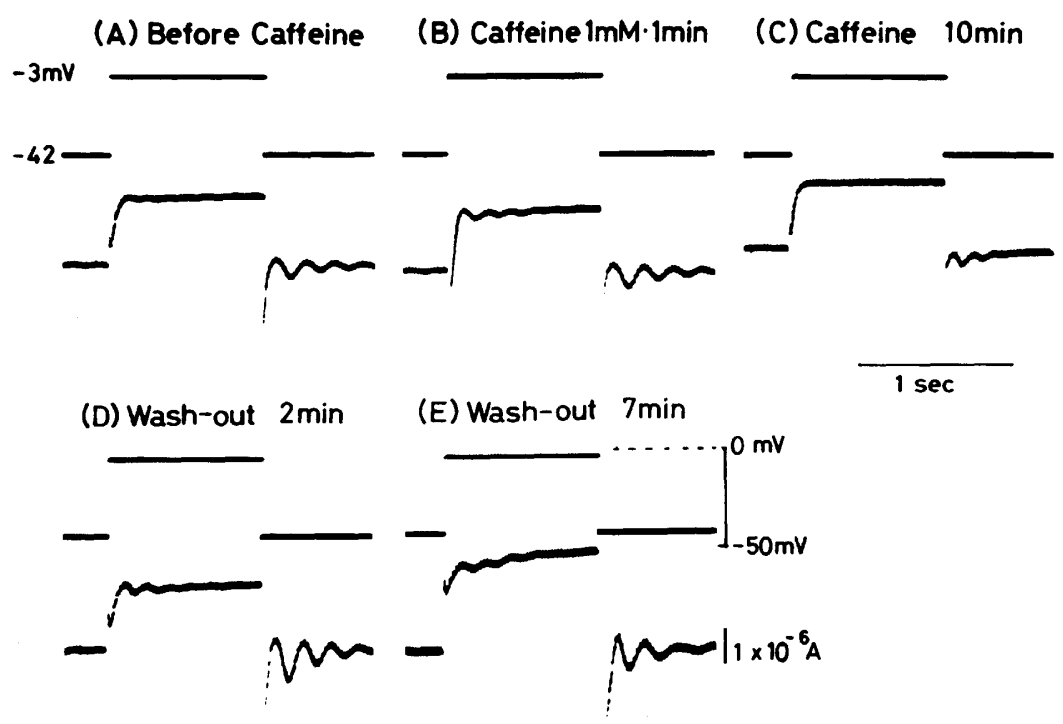

Fig. 8. Effects of $1 \mathrm{~mm}$-caffeine on membrane currents of the guinea-pig ventricular muscle in the low- $\mathrm{K}^{+}$, high- $\mathrm{Ca}^{2+}$ solution. The arrangements of the traces are the same as in the previous figures.

(A) Before Caffeine

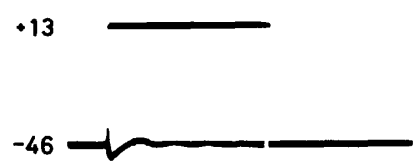

$-$

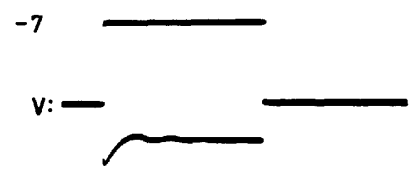

$1:-$
(B) Caffeine $10 \mathrm{mM}$
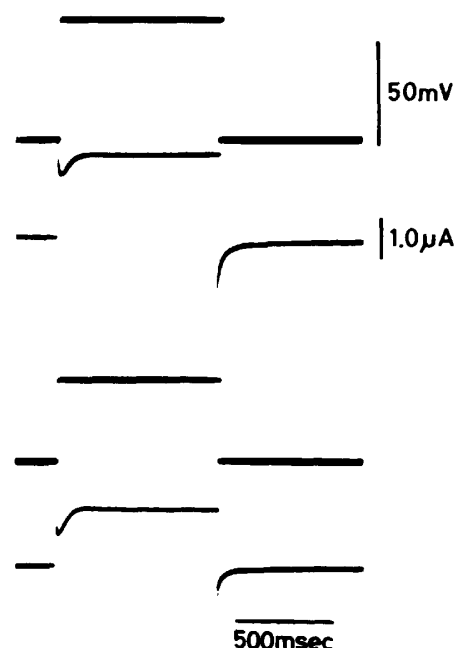

Fig. 9. Abolition of TI with application of $10 \mathrm{~mm}$-caffeine. During the application of $10 \mathrm{~mm}$-caffeine (B), TI was completely abolished, while $I_{\mathrm{s}}$ was mildly suppressed. The depression of the late outward current was also noted in B. 
These changes upon the wash-out of the drug were always observed in 7 preparations. A high concentration $(10 \mathrm{~mm})$ of caffeine was found to eliminate TI quickly without a transient augmentation at an early period of the application. Within $10 \mathrm{~min}$ of the application, $10 \mathrm{mM}$-caffeine completely abolished TI despite a mild inhibition of $I_{\mathrm{s}}(88 \pm 4 \%$ of the control at $10 \mathrm{~min} . n=4)$ (Fig. 9).

\section{DISCUSSION}

The present study disclosed that the manipulations which suppressed the slow channel produced inhibition of the transient inward current as rapidly as they did on the slow inward current in guinea-pig ventricular muscles under the low- $\mathrm{K}^{+}$, high- $\mathrm{Ca}^{2+}$ condition. Removal of their inhibition upon the wash-out of $\mathrm{Co}^{2+}$ or by raising external $\mathrm{Ca}^{2+}$ also developed as close a time course as the recovery of $I_{\mathrm{s}}$. Thus, there was no time lag between the action of these agents on $I_{\mathrm{s}}$ and those on TI. Further, procaine and caffeine, which are known to affect the $\mathrm{Ca}^{2+}$-uptake and -release from the sarcoplasmic reticulum (ENDO, 1977; Chapman, 1979; Fabiato, 1983), completely eliminated the TI despite a mild depression of $I_{\mathrm{s}}$. Since various experimental results suggest that the increase in internal $\mathrm{Ca}^{2+}$ is a key step in the generation of TI (FERRIER, 1977; KASS et al., 1978b; EISNER and LEDERER, 1979; KASS and TsIEN, 1982; MATSUdA et al., 1982), our observation may be compatible with the idea that $\mathrm{Ca}^{2+}$-influx through the slow channel upon each depolarization acts not only to load the cell with $\mathrm{Ca}$ ions, but also to produce somehow a phasic increase in $\left[\mathrm{Ca}^{2+}\right]_{\mathrm{i}}$ upon repolarization. Although the linking mechanism between the $\mathrm{Ca}^{2+}$-influx and the phasic increase in $\left[\mathrm{Ca}^{2+}\right]_{\mathrm{i}}$ is not known, the final step of the latter seems to trigger the $\mathrm{Ca}$ release from the sarcoplasmic reticulum.

The present result that the application of $\mathrm{Co}^{2+}$ or of $\mathrm{Mn}^{2+}$ rapidly suppressed the TI with a close correlation of the time course of the $I_{\mathrm{s}}$ inhibition is somewhat different from the observation made by Kass et al. (1978a) in digitalized Purkinje fibers. They noted that the development and removel of the TI inhibition lagged far behind its effect on the $I_{\mathrm{s}}$. Therefore, they concluded that the main action of $\mathrm{Mn}^{2+}$ was to reduce TI, indirectly, through its effect on $I_{s}$, thus causing an elimination of the $\mathrm{Ca}^{2+}$-overload in the cell. It is not certain, however, why two studies gave different results. But there may be a possible factor which accounts for the above discrepancies - a different condition used in both experiments in order to load the cell with $\mathrm{Ca}$. While we exposed the preparations to the low-K ${ }^{+}$, high-Ca ${ }^{i+}$ solution for about 15-30 min, they applied the drug, acetylstrophanthidin, to Purkinje fibers for more than $60 \mathrm{~min}$ for this end. It is, therefore, probable that the degree of the $\mathrm{Ca}^{2+}$-overload in our preparations is not equal to that of their preparations. The binding of the cardiac glycoside to the membrane may also induce a continued accumulation of $\mathrm{Ca}$ into the cells, despite a presence of $\mathrm{Mn}^{2+}$ in the latter condition. It has been pointed out that differences of $\mathrm{Ca}^{2+}$-overloading in the cells might account for discrepant results when inhibitory effects of the $\mathrm{Ca}^{2+}$-channel blocking agents on TI were examined. AlLEN et al. (1984) reported that the 
application of D-600 to the preparations, which were loaded with $\mathrm{Ca}^{2+}$ through the $\mathrm{Na}^{+}-\mathrm{Ca}^{2+}$ exchange mechanism, did not produce the decrease in the $\left[\mathrm{Ca}^{2+}\right]_{i}$ oscillations detected by the aequorin signals and in the aftercontractions, while KASS and TSIEN (1982) observed the decreased current fluctuations driven by the intracellular $\mathrm{Ca}$ oscillations in the $\mathrm{Ca}^{2+}$-overloaded preparations by exposure to digitalis or $\mathrm{K}^{+}$-free solutions in the presence of D-600. In spite of the above discrepancies, removal of external $\mathrm{Ca}^{2+}$ quickly inhibited both $I_{\mathrm{s}}$ and $\mathrm{TI}$ in the previous studies (KASS et al., 1978a; EISNER and LEDERER, 1979; KASS and TSIEN, 1982) as well as the present one (Fig. 6). Our result also agrees with the observations that $\mathrm{Mn}^{2+}$ suppressed DADs in other preparations including digitalized Purkinje fibers within a few min after the application (FERRIER and MoE, 1973; Rosen et al. . 1974; HiRAOKA et al., 1981). In the generation of TI, therefore, the $\mathrm{Ca}^{2+}$-influx through the slow channel acts as a major source of the cell-loading with $\mathrm{Ca}^{2+}$ as suggested by KASS et al. (1978a), and it also has some additional role in the increase in $\left[\mathrm{Ca}^{2+}\right]_{\mathrm{i}}$, depending on cellular conditions.

As to the generation of TI, the phasic release of $\mathrm{Ca}^{2+}$ from the intracellular stores is implicated (KASs et al., 1978b). If the role of $I_{\mathrm{s}}$ is applied to this schema, the $\mathrm{Ca}^{2+}$-influx via the sarcolemma must regulate a certain linking step to influence the $\mathrm{Ca}^{2+}$-release process from the sarcoplasmic reticulum. One possible link between the two processes is that $\mathrm{Ca}$ ions entering via the slow channel are rapidly taken up into the sarcoplasmic reticulum and transported to their release sites during the depolarization. Therefore, the more releasable $\mathrm{Ca}^{2+}$ is available upon repolarization or subsequent stimulations, when the amount of $\mathrm{Ca}^{2+}$ carried by $I_{\mathrm{s}}$ becomes larger, or vice versa. FABIATO (1983) suggested that $\mathrm{Ca}^{2+}$ transported through the slow channel could be a triggering mechanism of the $\mathrm{Ca}^{2+}$-release from the sarcoplasmic reticulum, although the quantitative relation of these ions between the two processes as well as the detailed mechanism have not yet been clarified.

Even if we admit that $I_{\mathrm{s}}$ has some influence on the $\mathrm{Ca}^{2+}$-release process which produces TI, our results pose another problem. The TI in our preparations showed a bell-shaped dependence on the activation voltage with a maximum at about $+29 \mathrm{mV}$. Similarly, the voltage dependence of $I_{\mathrm{s}}$ was also bell-shaped but with $25 \mathrm{mV}$ shift to more negative values as compared to those of TI. The bell-shaped voltage dependence of two currents as well as that of tension agreed with the previous reports (MORAD and Goldman, 1973; Chapman, 1979). Further, a negative shift of the $I_{\mathrm{s}}$-voltage relation compared to the TI-voltage relation was also described in other tissues (KARAgueUzIAN and KatZUnG, 1982). Recently, MAYLIE and MORAD (1984) described a transient outward current related to Ca release and development of tension in elephant seal atrial fibers. This current had a bell-shaped voltage dependence similar to those of tension and of $I_{\mathrm{s}}$ with $20 \mathrm{mV}$ shift to more positive values compared to the latter two.

As the final step to produce TI, the role of the $\mathrm{Ca}^{2+}$-release from the stores was also supported by the present experiments. The applications of procaine and caffeine, which are known to affect the $\mathrm{Ca}^{2+}$-uptake and release from the 
sarcoplasmic reticulum (ENDO, 1977; Chapman, 1979; Fabiato, 1983), were shown to eliminate TI completely in spite of a mild depression of $I_{\mathrm{s}}$. The action of procaine on TI of the present experiment confirmed our previous observation of its inhibition on DADs (HIRAOKA and KaWANO, 1984), and agreed with the effects of tetracaine on them in Purkinje fibers (Bhattacharyya and Vassalle, 1981).

Recently, NOBLE (1984) indicated that $I_{\mathrm{s}}$ had two components with different time courses. The slower activating component if produced by the $\mathrm{Na}^{+}-\mathrm{Ca}^{2+}$ exchange mechanism and is therefore related to the development of TI. If this explanation is correct, the inhibition of $I_{\mathrm{s}}$ directly correlates with the suppression of $\mathrm{TI}$, and at least part of the present results can be explained by this hypothesis. However, the quantitative relation between $I_{\mathrm{s}}$ and TI, as well as the actual proof of Noble's explanation, is to be clarified by future studies.

Caffeine has been shown to increase $\mathrm{Ca}^{2+}$-release from the sarcoplasmic reticulum (ENDO, 1977) and to decrease the rate of uptake by causing Ca release, thus depleting the stores (ChAPMAN, 1979; FABIATO, 1983). In addition to these effects, it also demonstrates multiple actions on membrane currents including $I_{\mathrm{s}}$ (EISNER et al., 1979; GoTO et al., 1979). In the present experiment, 1 mM-caffeine produced a transient increase in TI together with an increased $I_{\mathrm{s}}$. This result was also in accord with our previous observation of the caffeine effect on DADs (HiRAOKA et al., 1979). Augmentation of $I_{\mathrm{s}}$ by caffeine, however, has recently been found to be due to a decrease of the overlapping outward current and the actual changes were a progressive decrease of $I_{\mathrm{s}}$ after its application (HEss and WIER, 1984). If this was taken into account, initial increases in TI may be caused by increased $\mathrm{Ca}^{2+}$-release. This finding was also recently confirmed by the aequorin signal in Purkinje fibers (EISNER and VALDEOLMILlos, 1986). Later suppression or complete elimination by high concentration of caffeine can be reasonably explained by the inhibition of $\mathrm{Ca}^{2+}$-uptake and the depletion of the stores. This result confirmed the observation reported by EISNER and LEDERER (1982). Therefore, the above results are in line with the hypothesis that the generation of TI is largely dependent on the $\mathrm{Ca}^{2+}$-release from the sarcoplasmic reticulum.

The present result that the slow channel blocking agents could suppress the TI by somehow influencing both the cellular $\mathrm{Ca}$ overload and the $\mathrm{Ca}^{2+}$ release process, and the effects of these agents developed as rapidly as they inhibit $I_{\mathrm{s}}$, may have a clinical implication. DADs and triggered-activity are assumed to play a significant role in contributing to the genesis of arrhythmias (CRANEFIELD, 1977; FERRIER, 1977). The $\mathrm{Ca}^{2+}$ antagonists are known to block the arrhythmias based on the slow response activity. In addition to this effect, they can also exert antiarrhythmic action directly on the triggered-arrhythmias based on DADs because of their inhibitory effect on the TI as demonstrated in this study.

This work was supported by the Research Grant (C 57-1, 1982) for Cardiovascular Diseases from the Ministry of Health and Welfare of Japan. 


\section{REFERENCES}

Allen, D. G., Eisner, D. A., and OrChard, C. H. (1984) Characterization of oscillations of intracellular calcium concentration in ferrent ventricular muscle. J. Physiol. (Lond.), 252: 113-128.

Bhattacharyya, M. L. and Vassalle, M. (1981) The effect of local anesthetics on strophanthidin toxicity in canine cardiac Purkinje fibres. J. Physiol. (Lond.), 312: 125142.

Charpman, R. A. (1979) Excitation-contraction coupling in cardiac muscle. Prog. Biophys. Mol. Biol., 35: 1-52.

Cranefield, P. F. (1977) Action potentials, afterpotentials, and arrhythmias. Circ. Res., 41: 415-423.

EISNER, D. A. and LeDERER, W. J. (1979) Inotropic and arrhythmogenic effects of potassium depleted solutions in mammalian cardiac muscle. J. Physiol. (Lond.), 294: 255-277.

EISNER, D. A. and LEDERER, W. J. (1982) Effects of caffeine on the transient inward current in cardiac Purkinje fibres. J. Physiol. (Lond.), 322: 48P-49P.

Eisner, D. A., Lederer, W. J., and Noble, D. (1979) Caffeine and tetracaine abolish the slow inward calcium current in sheep cardiac Purkinje fibres. J. Physiol. (Lond.), 293: 76P-77P.

Eisner, D. A. and VAldeolmillos, M. (1986) A study of intracellular calcium oscillations in sheep cardiac Purkinje fibres measured at the single cell lvel. J. Physiol. (Lond.), 372: 539-556.

Endo, M. (1977) Calcium release from the sarcoplasmic reticulum. Physiol. Rev., 57: 71108.

Fabiato, A. (1983) Calcium-induced release of calcium from the cardiac sarcoplasmic reticulum. Am. J. Physiol., 245: C1-C14.

FERrIER, G. R. (1977) Digitalis arrhythmias: Role of oscillatory afterpotentials. Prog. Cardiovasc. Dis., 19: 459-474.

FerRIER, G. R. and MoE, G. K. (1973) Effects of calcium on acetyl-strophanthidin-induced transient depolarizations in canine Purkinje tissue. Circ. Res., 33: 508-515.

Goto, M., Yatani, A., and Ehara, T: (1979) Interaction between caffeine and adenosine on the membrane current and tension component in the bullfrog atrial muscle. Jpn. J. Physiol., 29: 393-409.

HESS, P. and WIER, G. (1984) Excitation-contraction coupling in cardiac Purkinje fibers. Effects of caffeine on the intracellular $\left[\mathrm{Ca}^{2+}\right]$ transient, membrane currents, and contraction. J. Gen. Physiol., 83: 417-433.

Hirano, Y. and HiraOKa, M. (1986) Changes in $\mathrm{K}^{+}$currents induced by $\mathrm{Ba}^{2+}$ in guinea pig ventricular muscle. Am. J. Physiol., 251: $\mathrm{H} 24-\mathrm{H} 33$.

HiraoKa, M. and Kawano, S. (1984) Regulation of delayed afterdepolarizations and aftercontractions in dog ventricular muscle fibres. J. Mol. Cell. Cardiol., 16: 285-289.

Hiraoka, M., Oкамото, Y., and Sano, T. (1979) Effects of $\mathrm{Ca}^{++}$and $\mathrm{K}^{+}$on oscillatory afterpotentials in dog ventricular muscle fibers. J. Mol. Cell. Cardiol., 11: 999-1015.

HiraOKa, M., OKamoto, Y., and Sano, T. (1981) Oscillatory afterpotentials in dog ventricular muscle fibers. Circ. Res., 48: 510-518.

Karagueuzian, H. S. and Katzung, B. G. (1982) Voltage-clamp studies of transient inward current and mechanical oscillations induced by ouabain in ferret papillary muscle. J. Physiol. (Lond.), 327: 255-271. 
Kass, R. S., Lederer, J. W., Tsien, R. W., and Weingart, R. (1978a) Role of calcium ions in transient inward currents and after-contractions induced by strophanthidin in cardiac Purkinje fibers. J. Physiol. (Lond.), 281: 187-208.

Kass, R. S., Tsien, R. W., and Weingart, R. (1978b) Ionic basis of transient inward current induced by strophanthidin in cardiac Purkinje fibers. J. Physiol. (Lond.),281: 209-226

KASs, R. S. and TsIEN, W. (1982) Fluctuations in membrane current driven by intracellular calcium in cardiac Purkinje fibers. Biophys. J., 38: 259-269.

Kawano, S., Kinoshita, H., and Hiraoka, M. (1985) The mechanism of inhibitory action of $\mathrm{Co}^{2+}$ on the transient inward current. J. Mol. Cell. Cardiol., 17 (Suppl. 1): 72.

KOHLHARDT, M. and HAAP, K. (1980) On the mechanism underlying the cobalt-induced inhibition of slow inward current in mammalian ventricular myocardium. J. Mol. Cell. Cardiol., 12: 1075-1090.

LEDERER, W. J. and TsIEN, R. W. (1976) Transient inward current underlying arrhythmogenic effects of cardiotonic steroids in Purkinje fibers. J. Physiol. (Lond.), 263: 73-100.

Matsuda, H., Noma, A., Kurachi, Y., and Irisawa, H. (1982) Transient depolarization and spontaneous voltage fluctuations in isolated single cells from guinea pig ventricles: Calcium-mediated membrane potential fluctuations. Circ. Res., 51: 142-151.

MaYlie, J. and Morad, M. (1984) A transient outward current related to calcium release and development of tension in elephant seal atrial fibres. J. Physiol. (Lond.), 357: 267292.

McDonald, T. F. and Trautwein, W. (1978) Membrane currents in cat myocardium: Separation of inward and outward currents. J. Physiol. (Lond.), 274: 193-216.

Morad, M. and Goldman, Y. (1973) Excitation-contraction coupling in heart muscle: Membrane control of development of tension. Prog. Biophys. Mol. Biol., 27: 257-313.

NoBlE, D. (1984) The surprising heart; A review of recent progress in cardiac electrophysiology. J. Physiol. (Lond.), 353: 1-50.

Rosen, M. R., Ilvento, J. P., Gellband, H., and Marker, C. (1974) Effects of verapamil on electrophysiologic properties of canine cardiac Purkinje fibers. J. Pharmacol. Exp. Ther., 189: 414-422.

Wier, W. G., Kort, A. A., Stern, M. D., Lakatta, E. G., and Marban, E. (1983) Cellular calcium fluctuations in mammalian heart: Direct evidence from noise analysis of aequorin signals in Purkinje fibers. Proc. Natl. Acad. Sci. U.S.A., 80: 7367-7371. 